\title{
An Eco-Translatological Perspective on the Construction of China's Image: A Case Study
}

\author{
Shilong Tao, Xi Chen* \\ School of Foreign Languages, Hunan University, Changsha, China
}

*Corresponding Author: Xi Chen, School of Foreign Languages, Hunan University, Changsha, China

\begin{abstract}
This article aims to explore the construction of China's image in the English translation of 2019 Chinese Government Work Report (GWR) from the perspective of eco-translatology. The linguistic selections of the translation are analyzed and discussed from three-dimensional transformation within the adaptation and selection principle of ecological translation, namely linguistic, cultural and communicative. Since translating is a process of making choices and decisions, the investigation shows that China tends to build a considerate and friendly, cooperative and trustful, competent and responsible image towards other countries and the world, mainly with a translation strategy of domestication. Besides, the eco-environment of translation, like the policies of the Chinese government, the purposes of translation, and the positions of the initiator and target audience, makes a significant contribution to the translation of GWR, as well as the building of China's image.
\end{abstract}

Keywords: eco-translatology, China's image, 2019 Chinese Government Work Report (GWR), adaption and selection, three-dimensional transformation

\section{INTRODUCTION}

Since the founding of the People's Republic of China in 1949, in March of each year starting from 1954 as a tradition, the Chinese premier of the State Council would deliver the annual Government Work Report (GWR) to deputies of the National People's Congress (NPC) so as to ask for deliberation and approval, and to invite comments from members of the National Committee of the Chinese People's Political Consultative Conference (CPPCC). The GWR is mainly composed of the review of the work done in the past year, and the overall requirements and policy directions in economic and social development for the ongoing year where major tasks or goals to be undertaken are stated, covering almost all aspects and being a highly formulated discourse with relatively stable topics, schema, and style (Yu \& Wu, 2018: 75).

In the beginning years, the GWR is only delivered in Chinese during the session to Chinese people. With China's admission to the United Nations (UN) in 1971, the accession to the World Trade Organization (WTO) in 2001 and the building of Belt and Road Initiative (BRI) in 2013, more attention from other countries are drawn onto Chinese government's works and efforts, and Chinese government puts increasing emphasis on the translation of GWR, especially in its English version as English is the international and most widely spoken language around the world, which can directly display China's national images and powers towards the world. Therefore, the translations are designed to be nationalized and internationalized, indicating the government's awareness of the GWR's function as an important window for watching China (Wang, 2003).

The Chinese GWR is usually done by members of the Communist Party of China (CPC) and government officials, and their intended audience are the deputies of the NPC and the general public in China; while the English version is organized by the Central Compilation and Translation Bureau (CCTB), and their target readers are foreigner readers with different cultural backgrounds (Yu\&Wu, 2018: 84-85). The translating of the GWR often involves selected excellent professional Chinese translators and foreign scholars as advisors and proofreaders under strict governmental supervision, giving priority to the ideological correctness (Wang, 2014). Being as one of the most important political documents to build national images in China, the GWR is now ritualized and widely published by the Chinese government, especially over the last two decades. At home, the delivery of 
the GWR is broadcast live via China Central Television (CCTV); and overseas, its translations, most importantly in English, are released by some international media like Chinadaily.

Considering the active role of the Chinese government in this process of translating, this study aims to investigate the linguistic choices in the English version of the newest 2019 GWR and explore the construction of China's image under the basis of "adaptation and selection" in eco-translatology, with all the examples classified into three-dimensional transformations for discussion, respectively linguistic dimension, cultural dimension and communicative dimension. Since the translation functions in projecting the images of the Chinese government and transmitting the intended information to the implied audience in a globalized world (Bandar, 2012), there are two questions to be answered in this study: (1) what is the dominant translation strategy employed in the process of translating? (2) What kind of image of China is built in the translation?

\section{China's IMAGE BUILDing: AN ECO-TRANSLATOLOGICAL PERSPECTIVE}

\subsection{Building of China's Image}

The image of a nation or country in international system is argued to be one of the most significant notions constituting its international environment. Since K.E. Boulding firstly puts forward the concept of national image in his paper National images and International system, it has been a hot topic for a long time with the increasing of diplomatic activities between different countries. "The national image is always in some sense a product of messages received in the past and it is a highly structured piece of information-capital, developed partly by its inputs and outputs of information and partly by internal messages and its own laws of growth and stability" (Boulding, 1959: 121). It is a sum of all the characteristics recognized by individuals when they think about a country in the framework of the cognitive theory (Scott, 1965), and can be considered as a psychological cognition that can change people's previous thinking or consciousness set, arguing that "the key point of shaping a positive national image is to transmit effective information" (Jervis, 1970: 6).

Since China's admission to UN and WTO, China now plays an active international role in resolving international affairs as never seen before, and China's position and voice on the international stage is getting increasingly important. However, the image of China on the international stage is generally believed to be unfavorable as for a long time, China's international image has almost been dominated and shaped by Western media, being questioned, misunderstood and misinterpreted with a deep distrust and given a maliciously distorted account of Chinese realities (He, 2005; Xiang, 2013, Wu, 2019). As national image gives rise to the performance of a sovereign country or nation on the world stage and its public reaction in international communication $(\mathrm{Li}, 1999)$, the image-building of China has become a more urgent and practical task (Ramo, 2008; Barr, 2012; Wang, 2018), especially since China has launched the "Belt and Road Initiative" in 2013 to develop economic partnerships with countries and regions along the Eurasia and Euro-African continent.

Therefore, in recent years, the Chinese government has launched a series of image-building projects, including the establishment of overseas propaganda departments (Wang, 2003), the promotion of China's own English-language media (Alvaro, 2015), and the government-initiated and supervised translating activities like GWR (Yu \& Wu, 2018). Besides, the Chinese president Xi has also explicitly expressed his concerns for the building of China's image on many occasions these years, and urged publicity departments of all levels to tell good stories of China towards foreign audience for a correct and objective understanding (Huang, 2019: 54). In this social environment, the translation of GWR, an indispensable tool to project a desirable image of China to the world, is initiated by Chinese government itself, and there are no other interest conflicts from foreign media or people's comments in building China's image. In other words, the national image shaped in GWR is actually what the Chinese government wants to present to other countries in the world, but in order to provide true and accurate information about China, the translators must go through a translating process of "adaptation and selection".

\subsection{Analytical Framework}

"Adaptation and selection", an important concept in eco-translatology, was firstly put forward by Professor Hu Gengshen, a Chinese scholar from Tsinghua University in 2001 and developed at a fast speed in this decade, mainly drawing on the "natural selection" and "the survival of the fittest" of Darwin's evolutionary theory and traditional Chinese philosophy of "the harmony between man and 
nature". It focuses on the interrelation between translators and the translational environment, or the interactive relationship among the translators and audience, seeking for harmony and unity among all the participants involved (Hu, 2011: 97). Consequently, translation, in nature, can be seen as a kind of selection process of translator's adaptation to translational eco-environment. The whole process of translation can be illustrated as Figure 1 (Hu, 2004: 222).

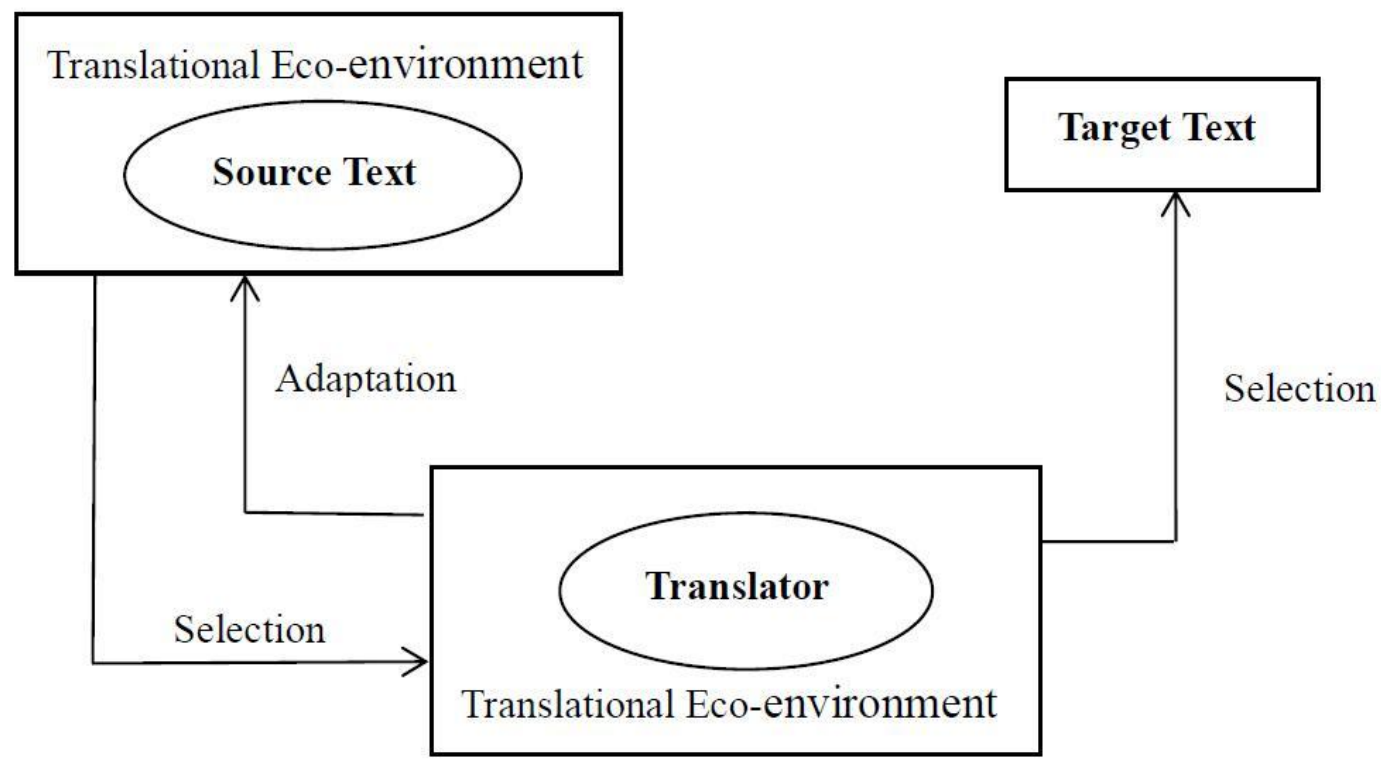

Figure1: The translation process of "adaptation and selection"

As shown in the above figure 1, it can be concluded that the process of translation is the translator's adaptation to the translational eco-environment and the translator's selection of the translational ecoenvironment, as well as the form of the final target text, which can be simplified into "translation as adaptation and selection" (TAS). Translational eco-environment here refers to the source text and the source or target languages which compromises the linguistic, communicative, cultural and social aspects of translation, as well as the author, the client and the readers (Hu, 2004: 220). Some western scholars also have mentioned this in the process of translation. For example, Newmark (1982: 19) notes that translation theories take care of the choices and decisions instead of the mechanic transitions between the source language text and the target language text; and Nida (2000: 7) points out a translator is required to make thousands of decisions related to selection and arrangement in order to adapt to a different culture or language, distinct editors and publishers and finally the readers.

However, in the view of eco-translatology, TAS is the instinct of translators to adapt to the social or natural environment and select proper words, phrases in the process of translation, and only the translator who can meet the demands and standards required by translational eco-environment can be selected as translators (Hu, 2014). In order to produce a better translation work, the translator needs to regard themselves as the center of nature in order to adapt to it, and then to select a better version that best fits the environment. Thus, the translator's choices of translation strategy will be shown at the same time, like foreignization, domestication, literal translation or free translation. As for the translation of GWR, it stands for the ideology of Chinese government who acts as the translator's centeredness under strict governmental supervision, and the translator's choices of shaping the national image in translation in fact demonstrate this "adaptation and selection".

Furthermore, when translating, the translator should attempt to adapt to the translational ecoenvironment and make selections to produce the target text, but it is impossible and impractical to require the translator to adapt to all the aspects and levels of the translational eco-environment. As a result, TAS in eco-translatology generalizes its translation principles as multi-dimensional transformation and adaptive selection, which falls into three dimensions, namely linguistic, cultural, and communicative dimension $(\mathrm{Hu}, 2011)$. The linguistic dimension requires translators to pay attention to language form and change it in translation if necessary; the cultural dimension asks translators to have a good knowledge of both cultures; and the communicative dimension needs translators to emphasize the communicative function of language. The more dimensions the translator adapts to, the more appropriate adaptive selection can be reached; and the higher the degree of multi- 
dimensional adaptation and adaptive selection is, the higher level of holistic adaptation and selection will be achieved.

\section{ANALYSIS AND DISCUSSION: THE CONSTRUCTION OF CHINA'S IMAGE IN TRANSLATION}

In this part, the linguistic choices and translation strategies in the English version of 2019 Chinese GWR, and the images of the Chinese government therefore projected in GWR will be discussed and analyzed. The examples are chosen from Chinadaily (http://language.chinadaily.com.cn/a/201903/18/ WS5c8efa3da3106c65c34ef20c.html), and they are placed into the three-dimensional transformation and adaptive selection, adopting a deductive and descriptive method.

\subsection{Adaptation and Selection in Linguistic Dimension}

Linguistic dimension is related to translator's decision on the representation of the original text at lexical, syntactic and textual levels (Hu, 2004: 134) as translation is basically a transformation of language, covering a text from one to another. The Chinese version of GWR is written in a typical political and official form, covering specific terms with Chinese characteristics. So, sometimes it may be difficult for translators to find equivalent words in English, and the translator is supposed to consider whether to keep the original wording, sentence pattern, and figure of speech or to follow the expression norms of the target language system. With the consideration of the target readers and the purpose of disseminating China's images, different strategies will be adopted in the process of translating GWR. Thus, the images established in translation will be clearer and more specific especially when the original text is written in an implicit way.

\section{Example 1:}

ST(1): 深入推进政治建军、改革强军、科技兴军、依法治军。(Deeply promote the policy in constructing armed forces, the reform in strengthening armed forces, the technology in upgrading armed forces, and the law in ruling armed forces.)

TT(1): We will further efforts to ensure the political loyalty of the armed forces, strengthen them through reform, science and technology, and run them in accordance with law.

ST(2)：中国愿与各国携手合作、同舟共济... (China wishes to cooperate with all other countries hand in hand and cross a river in the same boat...)

TT(2): China stands ready to work together with all other countries...

GWR is a kind of official written documents with political characteristics, so the word expressions tend to be more formal, concise and objective. Four-character structure is a traditional language-using habit to signal the formal occasions as the form is parallel and neat. It seems to be simple, but the translators should pay attention to interpreting the logical and deep meanings in it. For Example 1, in TT(1), the translator adjusts the logical order with one English verb "strengthen" to replace “强”(qiang) and “兴” (xing); and in TT (2), as “携手合作” (xie shou he zuo, work together) and “同舟共济”(tong zhou gong ji) in Chinese function as a "repetition" and have the similar meaning, the translator selects only one of them and translates it as "work together with all other countries" in a concise way.

It can be seen that in this linguistic dimension, the translator adopts a translation strategy of domestication to express the meaning of the original clearly in order to adapt to the habitual expression of the target language. With the selection of translating only one verb or term, or using a method of "combination", the translator aims to eliminate the misunderstanding and deviation caused by the differences in grammar and semantics between Chinese and English. Thus, in this process of translating, a considerate and kind China's image stands out as the translation gets rid of the original four-character pattern and is friendly-oriented for readers to understand.

\section{Example 2:}

ST(1): 加强科研伦理和学风建设, 惩戒学术不端, 力戒浮躁之风。(Strengthen research ethics and academic construction; punish academic misconduct; guard against rash action.)

TT(1): We will strengthen research ethics, improve academic practice, take disciplinary action against academic misconduct, and guard firmly against rash action. 
$\mathrm{ST}(2)$ : 我们将坚定不移走和平发展道路、奉行互利共赢的开放战略。(We will firmly go on the peaceful development road and pursue a win-win opening upstrategy.)

TT(2): China will remain on the path of peaceful development, pursue mutually beneficial opening up, and resolutely uphold multilateralism and the international system built around the United Nations.

It's a normal phenomenon that there is no subject in Chinese sentence. That's possibly because the tendency to omit personal nouns in Chinese wherever possible and keep the subject that consists of pronouns implicit (Lü, 1999: 8). For Example 2, in TT(1), "we" is added to show solidarity and communality with the hearers or readers, not only the people at home, but also those abroad. Based on the statistics manually collected, "we" in English version of 2019 GWR appears totally 594 times, while "我们” (we) in Chinese only appears 27 times. Although "we" in English can be either "inclusive" or "exclusive" (Levinson, 1983), the "we" selected here in GWR can refer to both the speaker and hearers, or China and other countries, which is inclusive and may help construct a chummy and intimate tone (Wales, 1996: 67).

By using the inclusive "we", the premier, on behalf of China, intends to be closely identified with his audience, which may function to diminish the distance between the speaker as premier and the listeners as representatives of the people, and the distance between the Chinese government as a governing body and the common people as being governed (Yu \& Wu, 2018: 80). Thus, a friendly and cooperative image of "China" foregrounds again, not a solemn one standing in a high position. Besides, in TT(2), “我们” (we) in source text is replaced as "China" to adapt to Chinese diplomatic strategy and show readers a responsible image of big country, indicating the determination of Chinese government, even the whole Chinese people aim to go on the path of peaceful development and pursue mutually beneficial opening up, and stressing the relationship between China and other countries, which highlights a cooperative image of China.

\section{Example 3:}

ST(1): 平衡好稳增长与防风险的关系, 确保经济持续健康发展。(Balance the relationship between keeping stable growth and against risks; ensure sustained healthy economic development.)

TT(1): we need to achieve the right balance in the relationship between maintaining stable growth and guarding against risks, to ensure sustained, healthy economic development.

ST(2):

把面向市场需求和弘扬人文精神结合起来, 善聚善用各类人才, 中国创新一定能更好发展, 为 人类文明进步作出应有贡献。(Combine the market-oriented demand with the promotion of humanistic spirit; good at gathering and using all kinds of talents; China's innovation must get better development; make contribution to the progress of human civilization.)

TT(2): By combining our response to market demand with a championing of the spirit of humanity, and by bringing together and using well capable people with talents of all kinds, we will be sure to see better development in Chinese innovation, and thus do our part for the progress of human civilization.

It's shown obviously in Example 3, the logical relation in Chinese between sentence and sentence is implicit; while in English, the logical relations are added more specific and clearer with lots of conjunctive elements. It implies the translator's adaptation to the differences in two languages for reader's convenience as Chinese language tends to give prominence to parataxis, while English hypotaxis (Nida, 1982; Lian, 1997). This in fact demonstrates the big difference of language-using habits in various countries and their cultural traditions. By nature, it results from the different modes of thinking between Chinese and western people. Chinese are influenced by the philosophy of "the harmony between man and nature" in traditional culture, thus laying emphasis on integration and pursuing harmony through the semantic association between words and sentences; while western people, affected by the idea of "separation of nature and man" in ancient Greece, focus on the use of logical grammar to express the logical relationship between sentences and within sentences (Yang, 2011: 122).

This selections of presenting the logical relation between sentence and sentence in English contributes to reducing the misunderstanding of foreign audience and tends to establish a relaxing reading 
environment, which suggests that Chinese government tries to help foreign readers have a better understanding on what China is doing now and what contributions it will bring so as to build a targeted, determined, and responsible national image. In this process of translating, it can also be looked as a transformation and adaptive selection from linguistic dimension to cultural dimension. Or in other words, it achieves the ecological balance of meaning, style and connotation between the source language and the target language.

\subsection{Adaptation and Selection in Cultural Dimension}

Cultural dimension focuses on the expression of the culture connotations behind the literal expressions of the original text as Saussure (2001) deems that language, as a kind of semiotic system of human communication, is the carrier of culture, which reflects different cultural psychology of different nations. In translation, the source and the target languages differ in historical background and cultural traditions involving the names, idioms, religions and customs, etc. Therefore, the translator should attach great importance to transformation in cultural dimension, which requires the translator to stand at an integral and global height and take the position of bridging two cultures, and to accurately transfer original cultural connotations and disseminate the source culture.

\section{Example 4:}

ST(1): 重点解决实现“两不愁三保障“面临的突出问题...(Focus on solving the prominent problems facing the realization of "two-not-worry and three-guarantee"...)

TT(1): We will give priority to our work of seeing that the basic living needs of rural poor populations are met and that such people have access to compulsory education, basic medical services, and housing...

ST(2)：...持之以恒纠治“四风”。(...keep on correcting and governing “Si feng”.)

TT(2): ....and keep up efforts to address formalities performed for formalities' sake, bureaucratism, hedonism, and extravagance.

In Example 4, “两不愁三保障” (liang bu chou san bao zhang) is a phrase embodying the political words of the Chinese times at present, and there is some information omitted in the original text. Here, the translator adopts a method of free translation with the consideration of current Chinese national conditions and policies to supply the specific information, which helps eliminate the misunderstanding of the policies carried out by Chinese government. As for “四风” (si feng) in ST(2), it is a specific name of the formalities. In Chinese tradition, “风” (feng, wind) means custom and etiquette, later in contemporary culture there is a certain expression of "X风” ( X feng), like “中国风” (zhongguo feng), “英伦风” (yinglun feng) which means the tendency or preference to do one thing. As shown in TT (2), the translator makes it more specific about what the “四风” (si feng) is instead of adopting literal translation, presenting the resolution to address the formalities of sake, bureaucratism, hedonism, and extravagance, which lays stress on the responsibility of Chinese government. Besides, there are many names of “a figure plus a term”, like “两个维护” (two weihu) and “四个自信” (four zixing). In the process of translation, the translator gives all the specific meanings of them in order to disseminate and improve the understanding of the China's culture.

\section{Example 5:}

ST(1)：...画好海内外中华儿女的最大同心圆,汇聚起共创辉煌的澎看力量。(Paint a good "concentric circle" of sons and daughters of China at home and abroad; gather the great strength to create brilliance together.)

TT(1): ...seek the greatest convergence of interests among all Chinese, both at home and overseas, and forge a mighty force, as we endeavor to create more remarkable achievements.

ST(2): 加快收费清单“一张网”建设, 让收费公开透明...(accelerate the construction of “a net” in charge list; let charging be open and transparent...)

TT(2): We will speed up the development of a comprehensive listing system for the collection of fees and charges... 
“同心圆” (tong xin yuan) here connotes the Chinese custom of making “a true love knot” as “圆” (yuan, round circle) or "knot" implies entirety and integration, closely binding together of two parts, very different from the meanings in western world like concentric zone theory; and "一张网" ( $y i$ zhang wang, one net) comes from the idiom of “一网打尽” (yi wang da jin, “catch all, letting none escape"). Here they present Chinese government's efforts to make charge collecting open and transparent in tax system and leave unauthorized charges no place to hide. In translating of these two terms, the translator takes the target cultural elements into consideration and adapts to the target system in a way of domestication so as to make the translated version intelligible and suitable for foreign audience, at the same time to build a solidary image of the Chinese government.

\section{Example 6:}

ST(1): 面对新情况新变化, 我们坚持不搞“大水漫灌”式强刺激...(Facing new circumstances and changes, we keep not to take a stimulation of "flood irrigation"...)

TT(1): Facing new circumstances and developments, we were firm in choosing not to adopt a deluge of strong stimulus policies...

ST(2): 这次减税, 着眼“放水养鱼”、增强发展后劲并考虑财政可持续...(This tax cutting aims to "pour water and feed fish", strengthen development potential and consider financial sustainability...)

TT(2): Our moves to cut tax on this occasion aim at an accommodative effect to strengthen the basis for sustained growth while also considering the need to ensure fiscal sustainability...

Similarly, in Example 6, these two Chinese idioms “大水漫灌” (da shui man guan, irrigation by flooding) and “放水养鱼” (fang shui yang yu, setting fish in water) are translated to adapt to the target culture in a way of domestication. "Da shui man guan" originally refers to an irrigating method used in agricultural production. Here it's translated as "a deluge of strong stimulus policies" to underline a moderate and firm image of China as shown by the policies or attitude in facing new circumstances and developments. "Fang shui yang yu" is a metaphor of "investing and creating a favorable environment for the development of the undertaking", and it's simply translated as "an accommodative effect", which may go far from the original culture meaning, but indicating the translator's consideration for readers as it fits to the style of an official document and can be easily understood in the context of sentences.

\subsection{Adaptation and Selection in Communicative Dimension}

Communicative dimension concerns the transformation and communicative function of language as the translation should accurately convey the linguistic and cultural connotations of the source language to the target language readers, and more importantly, to achieve the purpose of bilingual communication (Hu, 2008: 146). Therefore, it requires the translator to know well the background knowledge, and the communicative purposes and emotions of the original text should fully and accurately convey the information to target readers. It can be said that the ultimate goal of the transformation of linguistic, cultural and communicative dimension in translation is to maintain the communicative ecology of the source text and target text. Besides, considering the building of China's image, the translator in the process of translating needs to make selections in mood and modality of language so as to adapt to the translational eco-environment and form the final target text.

\section{Example 7:}

ST(1):

...事不避难、义不逃责, 埋头苦干、结合实际创造性地干, 努力干出无愧于人民的新业绩, 干 出中国发展的新辉煌。(...never sidestep difficulties or shirk obligations; work hard and be creative in practice; try to make new achievements worthy of the people; make remarkable new accomplishments for China's development.)

TT(1): ...We must never sidestep difficulties or shirk obligations; we must knuckle down and work hard, and be creative while aware of what is feasible. We should make new achievements worthy of our people and make remarkable new accomplishments in pursuing China's development.

ST(2):

加强与主要大国沟通对话与协调合作，深化同周边国家关系，拓展与发展中国家互利合作。 
(strengthen the communication, dialogue and cooperation with major countries; deepen relations with neighboring countries; expand mutually beneficial cooperation with developing countries.)

TT(2): We will strengthen communication, dialogue, coordination, and cooperation with other major countries. We will deepen relations with our neighbors and expand mutually beneficial cooperation with other developing countries.

As illustrated in Example 7, there are no characters specifically expressing the meanings of the modal auxiliary verbs of "must", "will" or "should". According to the rough statistics collected, "must" appears 49 times, "will" appears 430 times and "should" appears 36 times in English version of 2019 GWR; while “必须” (must) in Chinese text only appears 8 times, “要” (or “将要”, will or must) appears 136 times and “应” (or “应该”, “should”) appears 4 times. Furthermore, the mood type in the source text is "imperative" to show the determination, while the target text is almost changed into "indicative" as statements to give information to readers.

With the adding of modality elements and the changing of mood types, an authoritative and competent image of China who is responsible and determined to solve tasks and make remarkable accomplishments, and strengthen relations with our neighbors and expand mutually beneficial cooperation with other developing countries, seems to be created as China intends to regard all his words as definite and indisputable, which pictures the internal goal and external strategy of Chinese government, and helps to establish a trustful image for target audience, thus achieving the communicative function between the speakers and hearers.

\section{Example 8:}

ST(1)：...广泛开展群众性精神文明创建活动。(...widely carry out public spirit and civilization construction activities)

TT(1): We will...carry out a broad range of public activities to promote cultural and ethical advancement.

ST(2): 对外开放全方位扩大, 共建“一带一路”取得重要进展。(All aspects of opening up have been expanded and important progress has been made in building "one belt and one road".)

TT(2): Opening up was expanded on all fronts, and joint efforts to pursue the Belt and Road Initiative (BRI) made significant headway.

“精神文明” (jing shen wen ming) in Example 8 is a traditional expression in China, and the background knowledge refers to the public activities of altering old customs and habits such as promoting "national reading". The translator interprets it as "cultural and ethical advancement" in a strategy of domestication, free from the original literal expression or being equivalent in form. This may minimize the cultural strangeness felt by the target readers. What's more, it's worth mentioning that in the 2010 GWR, the term “精神” (jing shen) and “文明” (wen ming) was translated as “spirit” and “civilization", like “精神家园” (jing shen jia yuan) was translated as "a home of spirit" and “人类文明进步” (ren lei wen ming jin bu) as “the progress of human civilization". But later, in recent GWRs, all the translations of these terms are changed into other words, trying to avoid the using of "spirit" and "civilization".

For example, “精神文化生活” (jing shen wen hua sheng huo) is translated as "intellectual and cultural life" and “生态文明” (sheng tai wen ming) as “ecological improvement”. This selection of the translation indicates the Chinese government's awareness to build a good and practical image, since "spirit" has the meaning of "the soul thought of as separate from the body" and "civilization" has meaning of "a society, its culture and its way of life during a particular period of time, especially in past" in terms of Oxford English Dictionary. Thus, the translator directly conveys the meanings in linguistic and cultural dimensions to target readers so that the communicative intentions can also be achieved.

As for the translation of “一带一路”(BRI), this term firstly appeared in 2015 GWR and was translated as "The Silk Road Economic Belt and the 21st Century Maritime Silk Road", then in 2016 and 2017 was abbreviated to "The Belt and Road Initiative", and now is the "Belt and Road Initiative (BRI)". These changes in translations in fact show Chinese government's awareness to attach great 
importance to the communicative function of the translated text, and the word "initiative" also reflects that Chinese government is the initiator and leader of this policy in linguistic dimension, implying that our country is now active and competent in the international stage as it is in line with China's current international image and communicative purposes.

\section{CONCLuSion}

This study is the application of the "adaptation and selection" principle of eco-translatology into the English translation of 2019 Chinese GWR. From the above analysis and discussion, an image of a considerate and friendly, cooperative and trustful, competent and responsible Chinese government is established with the translator's "selection and adaption" of linguistic choices in the three-dimensional transformation. But a text cannot be separated from its context, or here it refers to the translational eco-environment. It is of interest to consider the motivations behind these occurring linguistic choices that make up the production of translation. To account for China's image established in the translation, it is necessary to take the context into consideration as "no translations should ever be studied outside of the context in which it came into being" (Toury, 2012: 22).

Under the strict governmental supervision, the translation of GWR can be a "serious political task" (Wang, 2008: 45), thus the translation is highly related to China's ideology. Since China has played an increasingly important role in international affairs and seemingly become the leader of "economic globalization" in recent years with the carrying out of BRI and Asian Infrastructure Investment Bank (AIIB), China desires to improve its international status and influence. This may explain why there is a tendency to enhance the translation of GWR. As "peace" and "development" are still the themes of our era and the world today, China tries to pursue mutually beneficial opening up and deepen relations with neighbors and countries to build a human community with a shared future. Therefore, a main technique of domestication is adopted in translation in order to help intended readers better understand what China is doing and will do with implicitly inviting them to participate in the joint project of building a better future as "we" and "China" are used frequently in a friendly and responsible tone, and to show a competent image of China taking part actively in resolving and improving the internal and external affairs with many modal auxiliary verbs such as "must" and "will" added in a firm tone.

It should be noted that the focus of this study is on the construction of China's image projected through the linguistic choices and clues in translations from the perspective of eco-translatology, not equivalent to the images actually formulated in the mind of the implied audience, which may be of interest for further studies. Since translating is a process of making choices (Nida, 2000; Levý, 2012), this study not only investigates the linguistic selections and translation strategies of the translator in "selection and adaption", but also discusses the consequences and contextual considerations. As China is influential and indispensable in the international arena, the construction of China's image is urgent and practical now. However, China's image established in GWR is only part of the whole, some other images established or to be presented in other political discourse are still worth exploring.

\section{REFERENCES}

[1] Alvaro, J.J. (2015). Analyzing China's English-language Media. World English, 34 (2), 260--277.

[2] Bandar, A. (2012). Linking Critical Discourse Analysis With Translation Studies: An Example From BBC News. Journal of Language and Politics, 11 (3), 311-335.

[3] Barr, M. (2012). Nation Branding as Nation Building: China's Image Campaign. East Asia. 29 (1), 81-94.

[4] Boulding, K.E. (1959). National Images and International System. Journal of Conflict Resolution, (3), $120-131$.

[5] He, Y. (2005). US Media and the Image of China. Guangzhou: Southern Daily Press.

[6] Hu, G. (2004). An Approach to Translation as Adaptation and Selection. Wuhan: Hubei Education Press.

[7] Hu, G. (2008). Eco-translatology: A Primer. Chinese Translators Journal, 29(06), 11-15.

[8] Hu, G. (2011). Eco-features of Eco-translatology and the Implications to Translation Studies. Foreign Languages in China, 8(06), 96-99.

[9] Hu, G. (2014). An Eco-translatological Perspective on the Supersession of "Translator-centeredness" by "Translator's Responsibility". Chinese Translators Journal, 35(01), 29-35.

[10] Huang, L. (2019). Tell Chinese stories Well in the New Era: Value Leading, Topic Strategy and Significance of External Communication. Contemporary Communication, 05, 54-60. 
[11] Jervis, R. (1970). The Logic of Image in international Relations. Princeton: Princeton University Press.

[12] Levinson, S.C. (1983). Pragmatics. Cambridge: Cambridge University Press.

[13] Levý, J. (2012). Translation as a Decision Process. Scientia Traductionis, (11), 72-96.

[14] Li, S. (1999). International Relations and China's Diplomacy: A Unique Perspective of Moss Communication. Beijing: Beijing Broadcasting Institute Press.

[15] Lian, S. (1997). Contrastive Studies of English and Chinese. Beijing: High Education Press.

[16] Lü, S. (1999). Eight Hundred Characters in Modern Chinese. Beijing: The Commercial Press.

[17] Newmark, P. (1982). Approaches to Translation. Oxford: Pergamon Press.

[18] Nida, E.A. (1982). Translating Meaning. California: English Language Institute.

[19] Nida, E.A. (2000). A Fresh Look at Translating. Beeby A., Doris E., Marisa P. (eds.) Investing Translations. Amsterdam: John Benjamins Publishing Company.

[20] Ramo, J.C. (2008). China's Image: The Country in the Eyes of Foreign Scholars,Beijing: Social Sciences Academic Press.

[21] Saussure, F.D. (2001). Course in General Linguistics. Beijing: Foreign Language Teaching and Research Press.

[22] Scott, W.A. (1965). Psychological and Social Correlates of International Image. Kelman, H.C. (ed.). International Behavior: A Social-psychological Analysis. New York: Holt, Rinehart and Winston.

[23] Toury, G. (2012). Descriptive Translation Studies and Beyond. Amsterdam: John Benjamins Publishing Company.

[24] Wales, K. (1996). Personal Pronouns in Present-day English. Cambridge: Cambridge University Press.

[25] Wang, H. (2003). National Image Building and Chinese Foreign Policy. China, 1 (1), 46-72.

[26] Wang, N. (2018). Translation, Construction of China's Image and Overseas Dissemination. Foreign Language Education. 39 (05), 1-6.

[27] Wang, P. (2008). New Exploration on Translating Political Literature: Based on the Experience of Translating the Report on the Seventeenth National Congress of the Communist Party of China. Chinese Translators Journal, 01, 45-50.

[28] Wang, Y. (2014). On the Translation of Important Political Terms of the CPC Center Committee. Research on Translations from Chinese, 2(1), 47-64.

[29] Wu, Y. (2019). National Image Self-shaping and National Translation Planning: Concept and Strategies, Foreign Languages Research, 36(03), 72-78.

[30] Xiang, D. (2013). China's Image on International English Language Social Media. Journal of International Communication, 19 (2), 252-271.

[31] Yang, Y. (2011). Comparative Studies on Hypotaxis and Parataxis of English and Chinese Grammar. Journal of Hubei University (Philosophy and Social Science), 38(01), 120-124.

[32] Yu, H., \& Wu, C. (2018). Images of the Chinese Government Projected in its Work Reports: Transformation Through Translation. Lingua, 214, 74-87.

Citation: Shilong Tao, Xi Chen. An Eco-Translatological Perspective on the Construction of China's Image: A Case Study. "International Journal on Studies in English Language and Literature (IJSELL), vol 8, no. 1, 2020, pp. 1-10. doi: http://dx.doi.org/10.20431/2347-3134.0801001.

Copyright: () 2020 Authors. This is an open-access article distributed under the terms of the Creative Commons Attribution License, which permits unrestricted use, distribution, and reproduction in any medium, provided the original author and source are credited. 